\title{
BMJ Open Knowledge, attitude and practice of antibiotics and their determinants in Eritrea: an urban population- based survey
}

\author{
Mulugeta Russom (D) , ${ }^{1,2}$ Merhawi Bahta (D) , ${ }^{1}$ Merhawi Debesai (D) , ${ }^{1}$ Iyassu Bahta, ${ }^{1}$ \\ Abrahalei Kessete (D) , ${ }^{1}$ Aziza Afendi, ${ }^{1}$ Yodit Fitsum, ${ }^{1}$ Josephine Nambozi, ${ }^{3}$ \\ Solyana N Kidane, ${ }^{3}$ Eyasu H Tesfamariam ${ }^{4}$
}

To cite: Russom M,

Bahta M, Debesai M, et al. Knowledge, attitude and practice of antibiotics and their determinants in Eritrea: an urban populationbased survey. BMJ Open 2021;11:e046432. doi:10.1136/ bmjopen-2020-046432

- Prepublication history and additional supplemental material for this paper are available online. To view these files, please visit the journal online (http://dx.doi.org/10.1136/ bmjopen-2020-046432).

Received 06 November 2020 Accepted 13 September 2021

A) Check for updates

C Author(s) (or their employer(s)) 2021. Re-use permitted under CC BY-NC. No commercial re-use. See rights and permissions. Published by BMJ.

${ }^{1}$ National Medicines and Food Administration, Ministry of Health, Asmara, Eritrea ${ }^{2}$ Department of Medical Informatics, Erasmus Medical Centre, Rottordam, Netherlands ${ }^{3}$ WHO Country Office, Asmara, Eritrea

${ }^{4}$ Department of Statistics, Eritrean Institute Technology, Asmara, Eritrea

Correspondence to Mr Merhawi Bahta; meramcp19@gmail.com

\section{ABSTRACT}

Objective To measure knowledge, attitude and practice of antibiotics and antibiotic resistance (ABR) and their determinants in the Eritrean urban population.

Design A population-based, nation-wide, cross-sectional study.

Setting Urban settings of Eritrea.

Participants Members of the general public aged $\geq 18$ years and living in 13 urban places of Eritrea. Three-stage stratified cluster sampling was used to select the study participants.

Data collection and analysis Date were collected from July 2019 to September 2019 in a face-to-face interview using a structured questionnaire. The collected data were double entered and analysed using Census and Survey Processing system (V.7.0) and SPSS (V.23), respectively. Descriptive statistics, $\chi^{2}$ test, t-tests, analysis of variance, factorial analysis and multivariable logistic regression were performed. All analyses were weighted and $p<0.05$ was considered significant.

Primary and secondary outcome measures Main outcome variables were knowledge, attitude and practice of antibiotics and ABR. Secondary outcome measure was the determinants of knowledge, attitude and practice.

Results A total of 2477 adults were interviewed. The mean score of knowledge and attitude of antibiotics and $A B R$ was $10.36 / 20(S D=3.51$, minimum $=0$ and maximum $=20)$ and $22.34 / 30(S D=3.59$, minimum $=6$ and maximum $=30$ ), respectively. Of those who used antibiotics, the proportion of at least one inappropriate practice (use of antibiotics without prescription and/or discontinuation of prescribed antibiotics before completing the full course) was $23.8 \%$. Young age $<24$ years (adjusted odds ratio $(A O R)=1.61,95 \% \mathrm{Cl}: 1.08$ to 2.41$)$, male $\operatorname{sex}(A 0 R=1.48,95 \% \mathrm{Cl}: 1.14$ to 1.91$)$, higher level of education ( $A O R=1.76,95 \% \mathrm{Cl}: 1.08$ to 2.88$)$, and negative attitude towards appropriate use of antibiotics (AOR=0.95, 95\% Cl: 0.92 to 0.97 ) were found to be the significant determinants of inappropriate practice of antibiotics.

Conclusion The gap in knowledge and inappropriate practice of antibiotics in the Eritrean urban population was widespread; requiring immediate attention from policy-makers and healthcare professionals.
Strengths and limitations of this study

- This is among the few globally reported populationbased surveys covering nationwide representative of all urban residents of Eritrea.

- The study employed rigorous data quality and management approaches and had a high percentage of response.

- Results of this study were self-reported and thus, findings might be underestimated or overestimated, which might in turn have introduced information or recall bias.

- During data collection, though efforts were made to provide an equal chance of selection for every household member, there might be a selection bias as about three-fourth of the respondents were found to be females. This sex imbalance might be explained by the fact that the information regarding family size and available members during data collection was gathered without verification with an administrative list.

- The reliability and validity of the scales for knowledge and attitude on antibiotics were not checked using statistical tools.

\section{INTRODUCTION}

The excess use of antibiotics poses great health risks that would escalate bacterial resistance. ${ }^{1-4}$ Resistant infections are now estimated to cost at least 50000 lives each year in Europe and the USA alone. ${ }^{5}$ From this, one can speculate that the burden of antimicrobial resistance (AMR) would be much higher in resource-constrained countries in which the inappropriate use of antibiotics by healthcare professionals and consumers could be rampant. This in part is due to poor regulation, weak health systems, poor surveillance and knowledge, and higher infectious diseases. ${ }^{167}$ If left unimpeded, by 2050 , deaths attributable to AMR are estimated to be 10 million per year globally. ${ }^{1}$ 
Nowadays, antibiotic resistance (ABR) is recognised as one of the biggest threats to global health and is becoming a medical emergency that would limit the advances of healthcare delivery services. This endangers the achievements of the millennium development goals and also sustainable development goals. ${ }^{8}$ Thus, AMR in general and ABR in particular is transforming into a political agenda.

As estimated by the WHO, $80.0 \%$ of antibiotics are used in the community and $20.0 \%-50.0 \%$ of which are used inappropriately. ${ }^{9}$ Use of antibiotics without prescription, ${ }^{10-13}$ physician perception of patients expectation for antibiotics, ${ }^{14}{ }^{15}$ patient demand, ${ }^{16-18}$ unrestricted use of antibiotics ${ }^{719}$ and poor healthcare system ${ }^{20}$ have been reported among the main factors for the inappropriate use of antibiotics. To tackle this, at the 68th World Health Assembly, a global action plan was endorsed. ${ }^{21}$ One of the five global strategic objectives was to improve awareness and understanding about AMR $;{ }^{21}$ thus, all member states were recommended by the WHO to annually conduct antibiotic awareness week campaigns in a one-health approach. ${ }^{21}$

With these recommendations, Eritrea has been in a process of establishing an antimicrobial stewardship programme. Through a multisectoral approach, Eritrea has developed a national action plan for combating AMR that is expected to be effective in 2021. One of the four strategic objectives of the national action plan is 'raise awareness through education and training'. Moreover, the National Medicines and Food Administration of the State of Eritrea has published a medicines schedule that is expected to contribute towards the antimicrobial stewardship. Prior to implementation, knowing the current status and weakest links are important for policy decisions and to identify areas of intervention on tackling AMR. Even though there is existing evidence of poor knowledge and inappropriate practice of antibiotics in many countries, there is a paucity of nationwide data in Eritrea and other countries with similar socioeconomic profile. This study was, therefore, conducted to measure knowledge, attitude and practice of antibiotics and identify their key determinants in the Eritrean urban population. As there is no baseline data to start with and assess the effectiveness of the annually conducted antibiotic awareness week, the findings of this study could also be taken as a point of reference to assess relative changes in the determinants of change in practice.

\section{METHODS}

\section{Study design and area}

A cross-sectional study design, with a quantitative approach, was used. Eritrea is a country with an estimated population of 3.4 million. ${ }^{22}$ It has 6 administrative zones comprising 58 subzones in total. The country has five administrative levels namely: national, zonal, sub-zonal, local administration (Kebabi administration) and village/ block (village in rural or block in urban settings) levels.
The survey was conducted between July 2019 and September 2019 in all urban sites of the country. In Eritrea, there are a total of 13 cities and/or towns. The urban sites included in this study were three from Gash Barka, five from Debub, two from Semenawi Keih-Bahri and one city or town from each of the remaining three zones, namely, Anseba, Debubawi Keih-Bahri and Maekel (online supplemental file 1). A total of 25 sub-zones and 72 local administrations (Kebabi administration) located in the above-mentioned towns and/or cities were involved in the survey.

\section{Target population}

The target population of the study includes all members of the general public aged 18 years or above and living in the 13 urban places in which the survey was conducted.

\section{Sample size and sampling technique}

The sample size computational formula ${ }^{23}$ and procedures accommodating the multistage sampling technique ${ }^{24}$ is provided as supplemental material (online supplemental file 2).

\section{Data collection tools and approach}

A structured questionnaire (online supplemental file 3) was prepared by reviewing questionnaires of similar studies ${ }^{25-27}$ and was customised in such a way to reflect issues relevant to Eritrea. It was initially prepared in English and then translated into the common local language, Tigrigna. The questionnaire had four sections, namely: personal characteristics of the respondent; awareness and knowledge regarding antibiotics and ABR; attitude regarding the use of antibiotics and ABR; and practice of the general public on antibiotic usage.

Sixteen pharmacy professionals who had prior experience were recruited as data collectors. Close supervision was made by two principal investigators (MR and MB). Orientation was provided to data collectors in order to familiarise them with the survey objectives, questionnaire, principles of conducting an interview, data collection procedures, standards of practice, procedures for listing the households and the second-stage as well as third-stage sample selection of the households.

Prior to the main fieldwork, the questionnaire was pretested on five different clusters, which were not included in the main survey. These blocks are found in two local administrations of Asmara. Twenty-five households were interviewed from each selected block. The pretest aided in assessing accuracy of translation, ability of the questions to elicit appropriate information and ability of enumerators to administer the questionnaire. Moreover, it was helpful in estimating the time required to complete the questionnaire. The questionnaire was finally modified based on the results of the pretest.

Households were sampled with the assistance of the administration office after listing them in selected blocks. When eligible respondents were absent from their homes, at least three visits were made to increase the opportunity 
of participation in the survey. If the selected candidate was found to be unavailable in a successive of three-four attempts, it was considered as a 'no response'.

\section{Outcome measures}

The primary outcome measures were knowledge, attitude and practice of antibiotics and ABR in the urban setting of Eritrea. The secondary outcome measure was the determinants of knowledge, attitude and practice of antibiotics and ABR.

\section{Data analysis}

Data was double entered using Census and Survey Processing system (V.7.0) software package and exported to SPSS V.23. It was summarised by using weighted percentages and counts. Cross-tabulations and further analysis were also computed whenever relevant.

Kolmogorov-Smirnov test was used to check on the normality of the knowledge and attitude scores. Frequencies, percentages, mean (with SD) and median (with IQR) were used to describe the data, as appropriate. After using independent samples t-test and analysis of variance at bivariate level of analysis, factorial analysis was employed to assess the predictors of knowledge and attitude at multivariable level. To explore the association between the inappropriate practice of antibiotic and the categorical demographic characteristics, $\chi^{2}$ test was performed. To control potential confounders, variables that were found to have a $\mathrm{p}$ value less than 0.05 were subjected to multivariable analysis using logistic regression. In this study, a p value less than 0.05 , in all the analyses, is considered as significant.

\section{Operational definition}

Inappropriate practice

Refers to the act of self-medication with antibiotics and/ or self-discontinuation of a regimen of antibiotics. It was determined by assessing whether the last used antibiotics were prescribed by an authorised health professional and/or those who used antibiotics interrupted their treatment regimen before completing the full course.

\section{RESULTS}

\section{Demographic characteristics of the study participants}

A total of 2542 individuals were selected for the survey. Among the selected individuals, 2477 were successfully interviewed, making an overall response of $97.4 \%$. The demographic characteristics of the respondents are summarised in table 1 . The unweighted numbers reflect the actual observations at the time of the survey, whereas the weighted numbers reflect figures that have been adjusted by the probability of selection of the respondents (table 1).

\section{Awareness, knowledge and attitude on antibiotics and ABR}

Based on participants' response, $73.3 \%$ and $39.0 \%$ of the study population were aware of the term 'antibiotic' and 'ABR', respectively. The sources of information about antibiotics and ABR were mainly from health facilities $(39.6 \%)$, television $(31.5 \%)$ and other people $(10.1 \%)$.

Of the list of medicines provided to assess distinguishing antibiotics from non-antibiotics, $59.4 \%$ of the study population correctly identified penicillin, while only $44.8 \%$ and $11.9 \%$ correctly identified cotrimoxazole and ciprofloxacin, respectively. Besides, ibuprofen, ORS and paracetamol were correctly identified as non-antibiotics by $58.5 \%, 60.7 \%$ and $70.6 \%$ of the population, respectively.

Less than half $(36.6 \%-49.5 \%)$ of the study population correctly reported the indication of antibiotics for common illnesses. Majority of them reported that antibiotics can be used to treat viral infection $(63.4 \%)$, watery diarrhoea $(61.8 \%)$, common cold $(58.9 \%)$, dry cough $(54.2 \%)$ and dengue fever $(50.5 \%)$. Sixty one per cent of the study population also reported that antibiotics are not indicated for tuberculosis. Correct knowledge on when to stop taking antibiotics once they had begun treatment was in the majority $(83.3 \%)$ of the study population.

Over three-fourth $(78.2 \%)$ of the study population correctly reported that ABR is an issue that could affect them and their family and about two-third $(63.6 \%)$ correctly answered the definition of ABR. The proportion of the study population who knew that bacteria resistant to antibiotics can spread from person to person and those who reported that $A B R$ is an issue in other countries but not in Eritrea was about $59.0 \%$ in both cases.

The overall mean knowledge score on antibiotics and $\mathrm{ABR}$ was found to be $10.36 / 20(\mathrm{SD}=3.51$, minimum $=0$ and maximum $=20$ ). At bivariate level, males, Christians, those who were aged between 25 years and 54 years, those who had higher educational level, those having big family size and who were government employees were more likely to have better knowledge score. Besides, the study population residing in Maekel and Anseba zones had better knowledge score on antibiotics and ABR compared with those living in other zones (online supplemental file 4). At multivariable level, age $(\mathrm{p}<0.001)$, religion $(\mathrm{p}=0.003)$, educational level $(\mathrm{p}<0.001)$, family size $(\mathrm{p}=0.015)$, occupation $(\mathrm{p}<0.001)$ and zone $(\mathrm{p}<0.001)$ maintained their association with knowledge score (table 2). Educational level has the largest partial $\eta^{2}(6.8 \%)$, showing its prime role in prediction of the knowledge score (table 2 ).

A positive attitude to the majority of the attitude items was reported to be $82.0 \%-92.7 \%$ (table 3). However, a positive attitude towards appropriate disposal of antibiotics was documented in less than $50.0 \%$ of the study population (table 3 ). The overall mean attitude score was $22.34 / 30 \quad(\mathrm{SD}=3.59$, minimum $=6$ and maximum $=30)$. At bivariate level, males, those aged between 25 years and 54 years, those who had higher educational level, government employees and study population residing in Maekel and Anseba zones had better attitude score compared with their counterparts (online supplemental file 5). At the multivariable level, age $(\mathrm{p}=0.001)$, gender $(\mathrm{p}=0.001)$, educational level $(p<0.001)$, occupation $(p=0.003)$ and zone $(\mathrm{p}<0.001)$ maintained their significance as predictors of attitude score. Zone has the largest explanatory 
Table 1 Distribution of the study population, 18 years and above, on the knowledge, attitude and practice survey of antibiotics and ABR by background characteristics, 2019, Eritrea

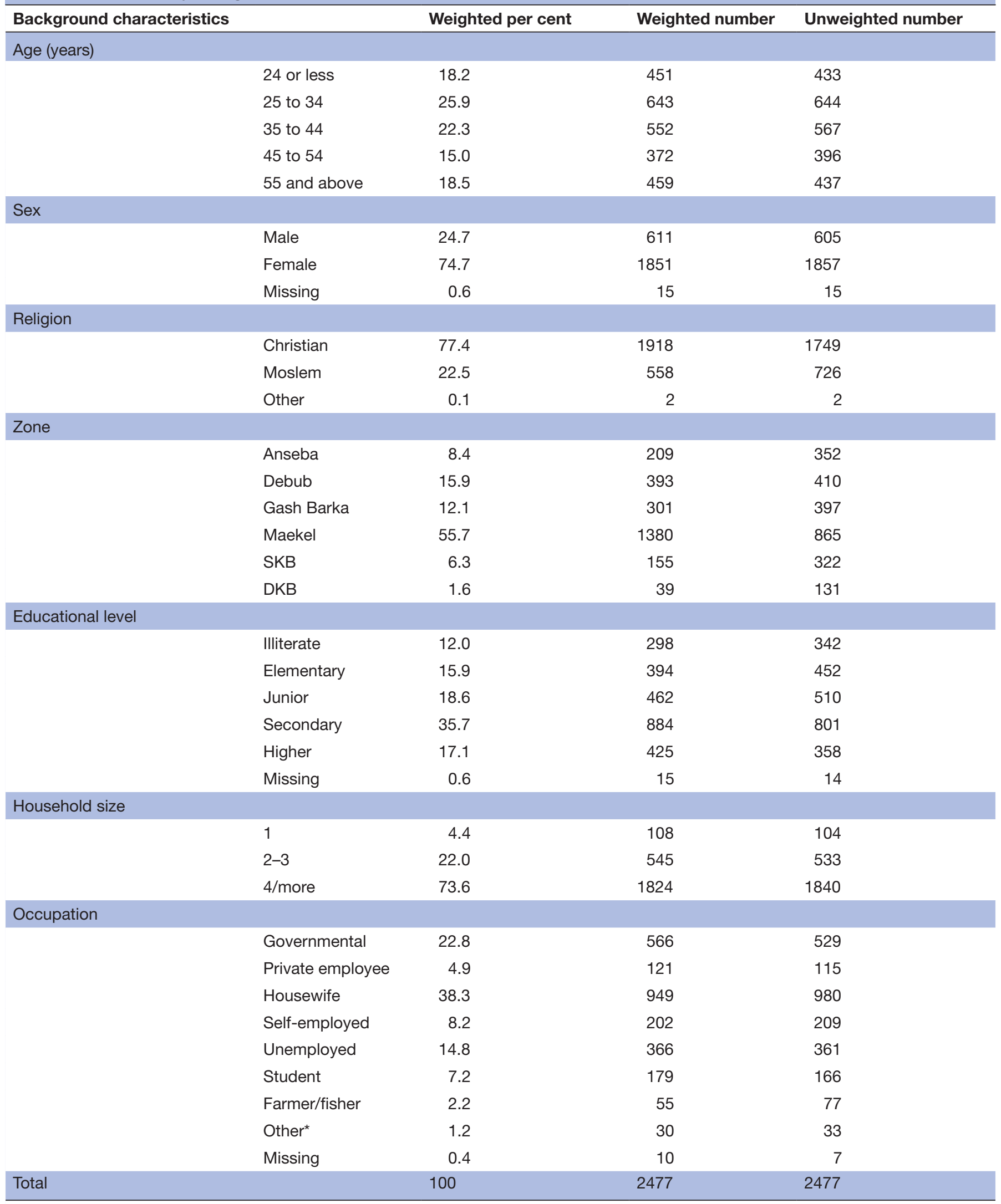

${ }^{*}$ Day labourer, soldier, sheik/priest, etc.

ABR, antibiotic resistance; DKB, Debubawi Keih-Bahri; SKB, Semenawi Keih-Bahri. 
Table 2 Predictors of knowledge and attitude towards antibiotics and ABR at multivariable level, Eritrea, 2019

\section{Knowledge}

\begin{tabular}{|c|c|c|c|c|}
\hline Predictor & $\mathbf{F}$ & $P$ value & Partial $\eta^{2}$ & $\begin{array}{l}\text { Observed } \\
\text { power }\end{array}$ \\
\hline Age (years) & 28.5 & $<0.001$ & 0.04 & 1.000 \\
\hline Gender & 0.4 & 0.536 & $<0.001$ & 0.095 \\
\hline Religion & 9 & 0.003 & 0.003 & 0.849 \\
\hline $\begin{array}{l}\text { Educational } \\
\text { level }\end{array}$ & 49.7 & $<0.001$ & 0.068 & 1.000 \\
\hline Family size & 4.2 & 0.015 & 0.003 & 0.738 \\
\hline Occupation & 6.3 & $<0.001$ & 0.014 & 0.999 \\
\hline Zone & 18.4 & $<0.001$ & 0.033 & 1.000 \\
\hline \multicolumn{5}{|l|}{ Attitude } \\
\hline Predictor & $\mathbf{F}$ & $P$ value & Partial $\eta^{2}$ & $\begin{array}{l}\text { Observed } \\
\text { power }\end{array}$ \\
\hline Age (years) & 4.5 & 0.001 & 0.007 & 0.944 \\
\hline Gender & 11.6 & 0.001 & 0.004 & 0.926 \\
\hline $\begin{array}{l}\text { Educational } \\
\text { level }\end{array}$ & 22 & $<0.001$ & 0.031 & 1.000 \\
\hline Occupation & 3.4 & 0.003 & 0.007 & 0.942 \\
\hline Zone & 21.6 & $<0.001$ & 0.038 & 1.000 \\
\hline
\end{tabular}

$\mathrm{ABR}$, antibiotic resistance.

(partial $\eta^{2}=3.8 \%$ ) capability for the attitude toward antibiotics (table 2). Additionally, the distribution of literacy with the significant determinants of knowledge and attitude scores are summarised in a supplemental material (online supplemental file 6).

\section{Practice on usage of antibiotics}

Majority (84.5\%) of the study population had used antibiotics at least once in their life time and $55.0 \%$ had a history of intake of antibiotics in the last 1 year and $12.3 \%$ in the last 1 month prior to commencement of this study. Of those who ever used antibiotics $(n=2407), 88.1 \%$ reported that their last intake of antibiotic(s) was prescribed by an
Source of antibiotics

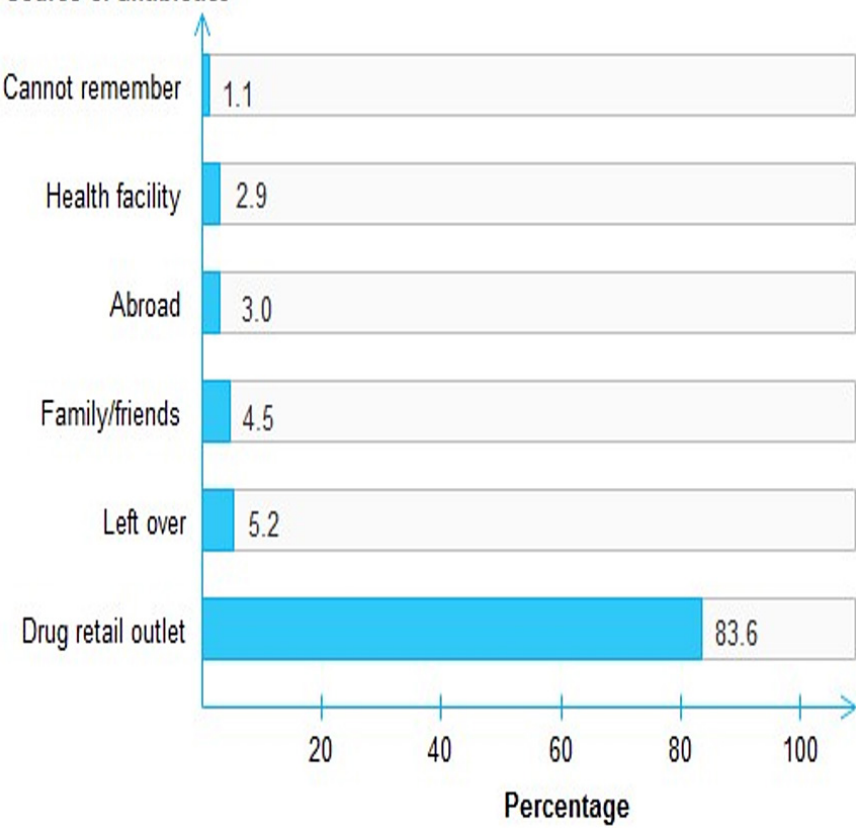

Figure 1 Source of antibiotics used without prescription among urban residents, Eritrea, 2019 ( $n=242)$.

authorised healthcare professional. Non-seriousness of the disease $(39.0 \%)$, need to get quick relief $(33.9 \%)$, previous own successful experiences $(16.1 \%)$, having no time to visit a health facility $(15.0 \%)$ and long queues existing in health facilities $(14.0 \%)$ were the top-five reasons reported for self-medication with antibiotics. For those who used antibiotics without prescription, the main sources of their last course of antibiotics were drug retail outlets $(83.6 \%)$ (figure 1$)$.

One-fifth $(18.8 \%)$ of those who had ever used antibiotics interrupted their regimen before completing the full course. The main reason for interruption of antibiotics was improved illness condition (63.4\%) (figure 2). About $3.0 \%$ of the study population reported that they had used antibiotics on their own at least once, though they were advised by healthcare professionals not to do so.

Table 3 Agree/strongly agree responses on the attitude of antibiotics usage and ABR, Eritrea, $2019(\mathrm{~N}=2477)$

\begin{tabular}{lc}
\hline Attitude questions on antibiotics usage and ABR & $\%$ (95\% Cl) \\
\hline Hand washing decreases ABR & 92.7 (91.6 to 94.1) \\
Taking antibiotics when it is not required can facilitate ABR & 89.7 (88.2 to 91.1) \\
You have a role to fight ABR & 85.8 (84.5 to 87.8) \\
It is not okay to share antibiotics with others & 90.1 (89.4 to 91.6) \\
We cannot use antibiotics without prescription & 88.0 (87.5 to 89.8) \\
Farmers should not give antibiotics without consulting veterinarian & 82.1 (80.9 to 83.7) \\
It is not okay to keep leftover antibiotics and use them later & 82.0 (80.7 to 83.5) \\
Leftover antibiotics should not be disposed with regular garbage & 46.0 (45.4 to 49.1) \\
Leftover antibiotics should not be disposed at toilets & 35.7 (34.3 to 37.9)
\end{tabular}

$\mathrm{ABR}$, antibiotic resistance. 


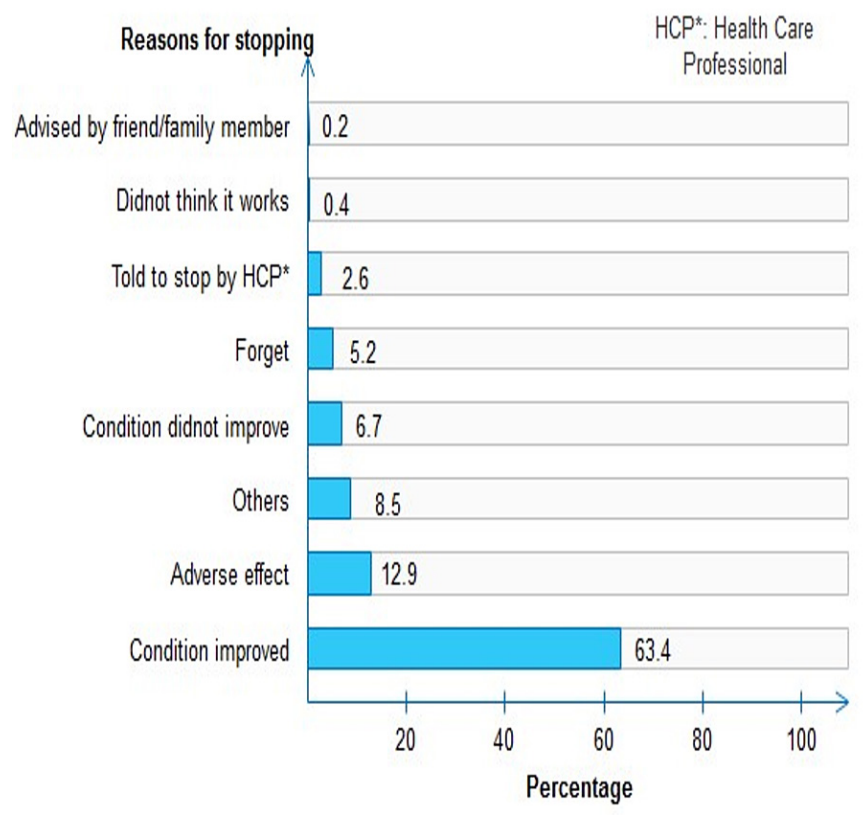

Figure 2 Reasons for stopping the intake of antibiotics among urban residents, Eritrea, 2019 ( $n=357)$.

Overall, inappropriate practice of antibiotics (use of antibiotics without prescription and/or self-discontinuation of prescribed antibiotics before completing the full course) was reported in $23.8 \%$ of the study population. The $\chi^{2}$ analyses found that age $(p<0.001)$, gender $(p=0.01)$, educational level $(p<0.001)$, occupation $(p<0.001)$ and zonal location $(\mathrm{p}<0.001)$ were the significant associates of inappropriate practice of antibiotics. The independent sample t-test showed that the mean attitude score of those in inappropriate practice $(\mathrm{M}=21.86, \mathrm{SD}=3.97)$ was significantly lower than those in safe practice $(\mathrm{M}=22.51$, $\mathrm{SD}=3.45)$. On multivariable level, those who were young, 24 years or less (adjusted odds ratio $(\mathrm{AOR})=1.61,95 \% \mathrm{CI}$ : 1.08 to 2.41 ), males (AOR=1.48, 95\% CI: 1.14 to 1.91 ), those who had higher level of education $(\mathrm{AOR}=1.76$, 95\% CI: 1.08 to 2.88 ) and those with higher attitude score (AOR=0.95, 95\% CI: 0.92 to 0.97 ) were more likely to involve in inappropriate practice of antibiotics (table 4).

A total of 1473 of the study population had animals and about $14.0 \%$ reported that they have treated their animals with antibiotics at least once. Of those who used antibiotics for their animals, $62.0 \%$ purchased at least once in the last year, prior to the study period. The commonly used antibiotics for animals were amoxicillin (44.1\%), oxytetracycline $(36.2 \%)$ and penicillin $(16.3 \%)$. About $51.0 \%$ of antibiotics used for animals were obtained from veterinarians, whereas the rest were mainly from pharmacy retail outlets $(20.8 \%)$, family/friends $(14.4 \%)$ and open markets $(14.3 \%)$ (figure 3$)$.

\section{DISCUSSION}

This nationwide urban population-based survey revealed a significant inappropriate practice of antibiotics in
Table 4 Predictors of inappropriate practice of antibiotics across the categories of demographic characteristics and attitude score at multivariable level, Eritrea, 2019

\begin{tabular}{|c|c|c|c|}
\hline \multirow[b]{2}{*}{$\begin{array}{l}\text { Background } \\
\text { characteristic }\end{array}$} & \multicolumn{3}{|c|}{ Multivariable analysis } \\
\hline & $\begin{array}{l}\text { Adjusted } \\
\text { odds } \\
\text { ratio }\end{array}$ & $95 \% \mathrm{Cl}$ & $P$ value \\
\hline Age (years) & & & 0.035 \\
\hline 24 or less & 1.61 & 1.08 to 2.41 & \\
\hline 25 to 34 & 1.26 & 0.89 to 1.79 & \\
\hline 35 to 44 & 1.05 & 0.74 to 1.48 & \\
\hline 45 to 54 & 0.89 & 0.61 to 1.29 & \\
\hline 55 or above & Ref. & & \\
\hline \multicolumn{4}{|l|}{ Gender } \\
\hline Male & 1.48 & 1.14 to 1.91 & 0.003 \\
\hline Female & Ref. & & \\
\hline Educational level & & & 0.103 \\
\hline Illiterate & Ref. & & \\
\hline Elementary & 1.02 & 0.66 to 1.57 & \\
\hline Junior & 1.19 & 0.77 to 1.83 & \\
\hline Secondary & 1.33 & 0.86 to 2.03 & \\
\hline Higher & 1.76 & 1.08 to 2.88 & \\
\hline Occupation & & & 0.183 \\
\hline Governmental & Ref. & & \\
\hline Private employee & 1.14 & 0.71 to 1.85 & \\
\hline House wife & 1.33 & 0.97 to 1.83 & \\
\hline Self-employed & 1.53 & 1.03 to 2.27 & \\
\hline Unemployed & 1.16 & 0.80 to 1.67 & \\
\hline Student & 1.43 & 0.93 to 2.19 & \\
\hline Farmer/fisher & 1.49 & 0.71 to 3.15 & \\
\hline Other* & 0.45 & 0.13 to 1.52 & \\
\hline Zone & & & 0.069 \\
\hline Anseba & 0.48 & 0.21 to 1.09 & \\
\hline Debub & 0.73 & 0.34 to 1.59 & \\
\hline Gash Barka & 0.70 & 0.32 to 1.57 & \\
\hline Maekel & 0.89 & 0.42 to 1.88 & \\
\hline SKB & 0.82 & 0.36 to 1.89 & \\
\hline DKB & Ref. & & \\
\hline Attitude score & 0.95 & 0.92 to 0.97 & $<0.001$ \\
\hline
\end{tabular}

*Day labourer, soldier, sheik/priest etc.

DKB, Debubawi Keih-Bahri; SKB, Semenawi Keih-Bahri.

Eritrea. One in five of the study population, who had ever used antibiotics, reported that their last intake of antibiotic(s) was self-interrupted for many reasons. The discontinuation of antibiotics when a consumer felt better was the most frequently reported reason. This reflects lack of awareness on the appropriate use of antibiotics and the risk of ABR. The majority of the antibiotics most recently consumed by the study population were reported to have 


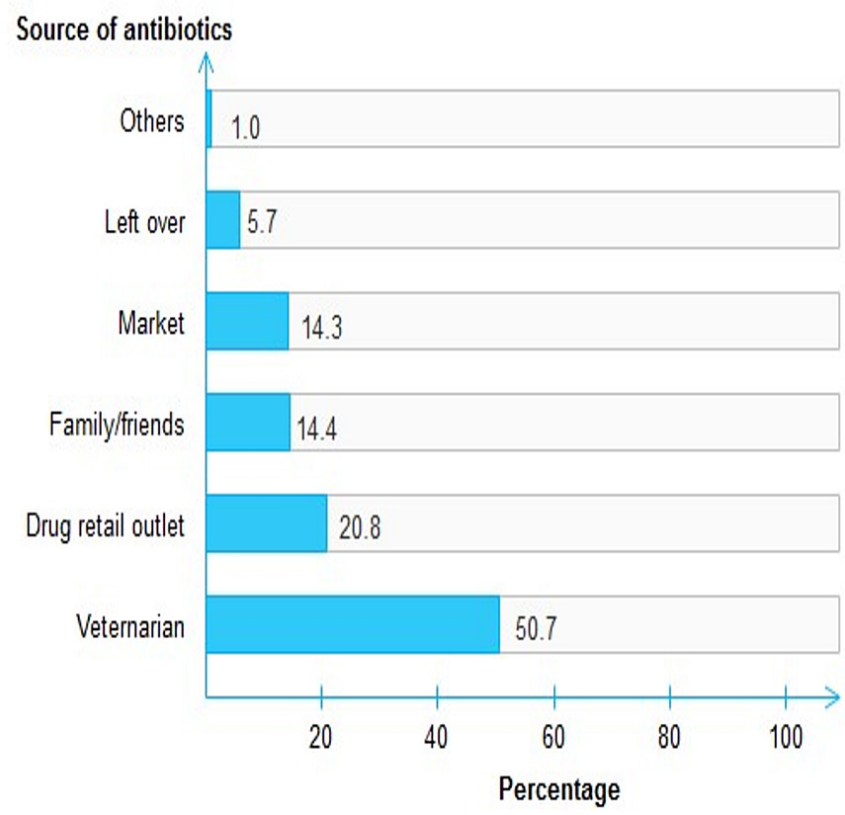

Figure 3 Source of antibiotics for animals among urban residents, Eritrea, $2019(\mathrm{n}=245)$.

been prescribed by qualified healthcare professionals. This is encouraging and the nationwide, massive antibiotic awareness week campaigns conducted in the last 3 years, prior to the study, might have had positive contributions. However, due to the lack of a national baseline data, the authors could not come up with a definitive conclusion regarding the effectiveness of the previously conducted campaigns.

The disease condition being non-serious, intention to get quick relief, previous successful experience, shortage of time to visit health facilities and long queues were the main triggering factors reported for self-medication with antibiotics. The first three reasons mentioned above for self-medication with antibiotics reflect lack of awareness on the risks of inappropriate use of antibiotics. In Eritrea, guided by 'health for all policy' and 'social justice', healthcare services are provided at a highly subsidised or nominal cost through public health facilities. To further improve patients' satisfaction, access to health services and health seeking behaviour, the existing healthcare delivery services need to be optimised. Moreover, the annual antibiotic awareness week campaign should be augmented by additional continuous and regular health promotional activities.

In this study, drug retail outlets were reported as the main sources for the sales of antibiotics without prescription. A recently conducted study also revealed an alarming picture; $87.0 \%$ of retail outlets found in Eritrea were dispensing antibiotics without prescription, ${ }^{10}$ which requires immediate attention from regulators and policymakers. Continued refresher courses on the appropriate use of antibiotics and ABR as well as further enforcement of regulations would have an impact in bridging these gaps. Cognizant of this, the National Medicines and Food
Administration of the Ministry of Health developed medicines schedule in 2019 and all antibiotics are put under the category of 'prescription-only medicine'. To ensure implementation and adherence to the scheduling terms, the National Medicines and Food Administration is recommended to conduct strict and continuous inspection on drug retail outlets.

Use of antibiotics without prescription in this study was more or less consistent with findings of similar studies conducted in European countries, where it was reported to occur in an average proportion of $7.0 \%$ (ranging from $0 \%$ to $20.0 \%) .{ }^{28}$ It was, however, much lower than that reported in Italy, ${ }^{29}$ Jordan, ${ }^{30} 31$ United Arab Emirates, ${ }^{32}$ Palestine, ${ }^{33}$ Lebanon, ${ }^{34}$ Iraq, ${ }^{35}$ Indonesia, ${ }^{36}$ Yemen, ${ }^{37}$ Saudi Arabia, ${ }^{38}$ Haiti, $^{39}$ Kuwait $^{40}$ and Ethiopia, ${ }^{41} 42$ where proportions ranged between $31.0 \%$ and $79.0 \%$. The variation in results, however, could be due to differences in study designs, study area, study population, type of questions and level of awareness of the study population. Following the WHO recommendation (2015) for all member states to start annual awareness raising programmes on AMR, Eritrea has started to implement it since 2016. This study was conducted after a few years of massive public campaigns and might have influenced the current findings. It is also possible that in other countries that have made similar initiatives, the existing profile might have been influenced in the same way despite no current studies are available.

Factors such as young age (24 years or less), male sex, high level of education and poor attitude score were identified as determinants of inappropriate practice of antibiotics. It is unknown why those who had higher level of education and those who were young (relatively with greater educational opportunities) were more involved in the inappropriate practice of antibiotics. This might to some extent be explained by the fact that knowing more or being educated predisposes people to a tendency to take self-made decisions more casually with the assumption that they have knowledge. Qualitative studies are required to further identify the determinants of inappropriate practice of antibiotics in the general public.

In this study, an appreciably good attitude score towards appropriate use of antibiotics and ABR was reported. It is, however, important to note that the poor attitude reported on the appropriate disposal of leftover antibiotics requires immediate attention from policy-makers. Studies on awareness and disposal practices of unused and expired medicines by consumers in India and Nigeria also reported that improper practices such as the disposal of medicines in domestic trash, toilets and sinks was prevalent. $^{43} 44$

Unlike the relatively good attitude score, the mean knowledge score of the study population on antibiotics and ABR was not satisfactory. This study revealed that the majority of the study population had no clear picture on what an antibiotic is and were unable to recognise, by name, the most commonly used antibiotics (penicillin, cotrimoxazole and ciprofloxacin) in 
the country. Categorising ibuprofen, ORS and paracetamol as antibiotics by a large number of the study population was another concern. A significant proportion of the study population also had the misunderstanding that antibiotics could treat viral infections like common cold and acute watery diarrhoea. Hence, continued awareness raising programmes should target such misconceptions and familiarise the public with the commonly used antibiotics, their proper indications and the potential for resistance. The assumption that ABR is a threat elsewhere but not in Eritrea, as reported in this study, reflects how oblivious people were to the issue of $A B R$ and this may limit the public from taking appropriate actions.

In this study, those who were aged between 25 years and 54 years, had higher educational level, were government employees or residing in Maekel and Anseba zones were significantly associated with higher knowledge and attitude scores. Literacy to a larger extent might explain, among others, the observed good knowledge and attitude scores in relation to the above predictors as all these categories had better educational levels (online supplemental file $6)$. However, more data are required to make accurate deductions with regard to these predictors. It is also important to note that the association observed with the above-mentioned variables do not seem to be clinically meaningful as a small difference in results could give statistically significant difference, and thus, readers should cautiously interpret the results. This emphasises the need for extensive awareness raising programmes for those who are illiterate and having lower level of education.

Regarding the use of antibiotics to treat animals, oxytetracycline, amoxicillin and penicillin were the most frequently reported ones. About half of the antibiotics used in animals were supplied by nonveterinarians such as drug retail outlets and open markets reflecting poor regulation of antibiotics in animal health.

Because parasites and infections do not respect borders, combating ABR has since long ago been a global agenda. A problem identified in one country could have direct or indirect implication on the containment of ABR by other countries. The significance of this nationwide survey and the results it comes up with are all expected to be of a particular interest for countries with similar socioeconomic status as Eritrea. Many of these countries share the common problem of poor quality, inequitable, overstretched, unregulated and poorly accessible health services, which could trigger the general public to be involved in inappropriate practice of antibiotics. Moreover, they lack the systems to control antibiotic consumption and the initiative to tackle the issue of resistance. If Eritrea's profile with regard to the prevalence of inappropriate practices such as selfmedication with antibiotics has been relatively good while there is a long way to go to improve the healthcare infrastructure, it is not hard to imagine the progress the country could assume if the existing policies such as the national action plan on AMR and regulations such as medicines scheduling are enforced.

This is among the few globally reported nationwide population-based surveys that measure knowledge, attitude and practice of antibiotics and ABR. The study employed rigorous data quality and management approaches and had a high percentage of response. On the other hand, one of the main limitations of this study was that the results were self-reported, and thus, findings might be underestimated or overestimated. This could introduce information or recall bias. Additionally, though efforts were made to provide an equal chance of selection for every household member, there might be a selection bias as about three-fourth of the respondents were found to be females. The sex imbalance might be explained by the fact that the information regarding family size and available members during data collection was gathered from the present household members, and no verification was made using an administrative list. Moreover, the reliability and validity of the scales for knowledge and attitude on antibiotics were not checked using statistical tools.

\section{CONCLUSION}

The inappropriate practice of antibiotics in Eritrea was prevalent and the young age, male sex, higher level of education and poor attitude towards appropriate use of antibiotics were identified as the determinants of inappropriate practices. The inability of a high proportion of the study population to distinguish antibiotics from other medicines and the reported misunderstanding that viral infections can be treated with antibiotics indicates limited knowledge on antibiotics and ABR. Continuous awareness raising programmes on the rational use of antibiotics (mainly on the risks of self-medication, treatment interruption and use of antibiotics for viral infections) and familiarising the public with the commonly used antibiotics are recommended. As drug retail outlets were identified to be the main sources for the supply of antibiotics without prescription, both in humans and animals, enforcement of medicines schedule and strengthening of regulatory inspections is vital. Besides, the huge gap in attitude towards appropriate disposal of antibiotics requires immediate attention from policy-makers and the establishment of an appropriate disposal system of leftover antibiotics for the community. Last but not least, it is high time to expedite the implementation of the strategies stipulated under the national action plan on AMR, which was released in February 2021.

Twitter Mulugeta Russom @Mulugeta.Russom 
Acknowledgements The authors sincerely thank the Ministry of Local Government and mayors of the administrative zones and their staff for the dedication they have shown in provision of demographic data, guidance and participation in the data collection process. Besides, the authors would also like to acknowledge the heads of the Zonal Pharmaceutical Services of all administrative zones for their collaboration and contribution in the data collection. We would also like to appreciate the following pharmacists for their invaluable contribution in data collection and data entry: Abel Tesfatsion, Abel Tekle, Adiam Andemariam, Asmerom Mosazghi, Dawit Ghebrehiwet, Freminatos Misghina, Habtemariam Berhane, Hagos Zerehaimanot, Hermela Yemane, Kibrom Shimendi, Luna Kiflay, Martha Amanuel, Michael Ghirmai, Michael Habteslassie, Michael Kidane, Natnael Bereket, Neamin Ghebremedhin, Niyat Belai, Nuru Abdu, Robel Werede, Samrawit Yonas, Selam Ghebrehiwet, Sirak Saleh, Sirak Tesfamariam, Yohana Berhane and Zebib Andemeskel.

Contributors The idea was conceived by MR and IB and designed by all authors (MB, MD, MR, AK, AA, YF, IB, SNK, JN and EHT). Data was collected by MD, AK, $A A$ and $Y F$ and supervised by MR and MB. EHT edited and analysed the collected data and all the co-authors participated in the interpretation of the results. The manuscript was drafted by MB, MR and EHT and critically reviewed and edited by all of the authors. Finally, all the co-authors agreed that the article be published in an international journal and to take responsibility and be accountable for its content.

Funding This work was funded by the WHO Country Office in Asmara, Eritrea (budget line: 1813144; 66415; 6.1).

Competing interests None declared.

Patient consent for publication Not applicable.

Ethics approval Ethical approval to conduct the study was obtained from the Ministry of Health, Eritrea, and further approval was also obtained from the Ministry of Local Government. Besides, informed consent was obtained from all study participants to take part in the study.

Provenance and peer review Not commissioned; externally peer reviewed.

Data availability statement Data are available upon reasonable request. All data relevant to the study are included in the article or uploaded as supplementary information. All data related to the study are included in the manuscript. The complete data-set used during the current study are available from the corresponding author and can be accessed upon reasonable request.

Supplemental material This content has been supplied by the author(s). It has not been vetted by BMJ Publishing Group Limited (BMJ) and may not have been peer-reviewed. Any opinions or recommendations discussed are solely those of the author(s) and are not endorsed by BMJ. BMJ disclaims all liability and responsibility arising from any reliance placed on the content. Where the content includes any translated material, BMJ does not warrant the accuracy and reliability of the translations (including but not limited to local regulations, clinical guidelines, terminology, drug names and drug dosages), and is not responsible for any error and/or omissions arising from translation and adaptation or otherwise.

Open access This is an open access article distributed in accordance with the Creative Commons Attribution Non Commercial (CC BY-NC 4.0) license, which permits others to distribute, remix, adapt, build upon this work non-commercially, and license their derivative works on different terms, provided the original work is properly cited, appropriate credit is given, any changes made indicated, and the use is non-commercial. See: http://creativecommons.org/licenses/by-nc/4.0/.

\section{ORCID iDs}

Mulugeta Russom http://orcid.org/0000-0003-1939-5842

Merhawi Bahta http://orcid.org/0000-0002-1690-7876

Merhawi Debesai http://orcid.org/0000-0002-2054-7818

Abrahalei Kessete http://orcid.org/0000-0001-9409-7226

\section{REFERENCES}

1 O'Neill J. Tackling drug resistance infections globally: final report and recommendations: the review on antimicrobial resistance. Government of the United Kingdom, London, United Kingdom 2016.

2 Hillier S, Roberts Z, Dunstan F, et al. Prior antibiotics and risk of antibiotic-resistant community-acquired urinary tract infection: a case-control study. J Antimicrob Chemother 2007;60:92-9.

3 Chung A, Perera R, Brueggemann AB, et al. Effect of antibiotic prescribing on antibiotic resistance in individual children in primary care: prospective cohort study. BMJ 2007;335:429.
4 Bell BG, Schellevis F, Stobberingh E, et al. A systematic review and meta-analysis of the effects of antibiotic consumption on antibiotic resistance. BMC Infect Dis 2014;14:13.

5 WHO. Antimicrobial resistance global report on surveillance: 2014 summary. Geneva: World Health Organization, 2014.

6 Malik B, Bhattacharyya S. Antibiotic drug-resistance as a complex system driven by socio-economic growth and antibiotic misuse. Sci Rep 2019;9:1-12.

7 Calbo E, Álvarez-Rocha L, Gudiol F, et al. A review of the factors influencing antimicrobial prescribing. Enferm Infecc Microbiol Clin 2013;31 Suppl 4:12-15.

$8 \mathrm{WHO}$. AMR indicators and their relevance to the global indicators framework for the SDGs and targets for the 2030 agenda for sustainable development 2018

9 WHO. The world health report 2007: a safer future: global public health security in the 21 st century. Geneva: World Health Organization, 2007.

10 Bahta M, Tesfamariam S, Weldemariam DG, et al. Dispensing of antibiotics without prescription and associated factors in drug retail outlets of Eritrea: a simulated client method. PLoS One 2020;15:e0228013.

11 Ateshim Y, Bereket B, Major F, et al. Prevalence of self-medication with antibiotics and associated factors in the community of Asmara, Eritrea: a descriptive cross sectional survey. BMC Public Health 2019;19:726.

12 Gebeyehu E, Bantie L, Azage M. Inappropriate use of antibiotics and its associated factors among urban and rural communities of Bahir Dar City administration, Northwest Ethiopia. PLoS One 2015;10:e0138179.

13 Ocan M, Obuku EA, Bwanga F, et al. Household antimicrobial selfmedication: a systematic review and meta-analysis of the burden, risk factors and outcomes in developing countries. BMC Public Health 2015;15:742.

14 McKay R, Mah A, Law MR, et al. Systematic review of factors associated with antibiotic prescribing for respiratory tract infections. Antimicrob Agents Chemother 2016;60:4106-18.

15 Cockburn J, Pit S. Prescribing behaviour in clinical practice: patients expectations and doctors' perceptions of patients' expectations--a questionnaire study. BMJ 1997;315:520-3.

16 Vanden Eng J, Marcus R, Hadler JL, et al. Consumer attitudes and use of antibiotics. Emerg Infect Dis 2003;9:1128-35.

17 Palmer DA, Bauchner H. Parents' and physicians' views on antibiotics. Pediatrics 1997;99:e6.

18 Bauchner H, Pelton SI, Klein JO, Parents KJO. Parents, physicians, and antibiotic use. Pediatrics 1999;103:395-401.

19 Kalungia AC, Burger J, Godman B, et al. Non-prescription sale and dispensing of antibiotics in community pharmacies in Zambia. Expert Rev Anti Infect Ther 2016;14:1215-23.

20 Kardas P, Devine S, Golembesky A, et al. A systematic review and meta-analysis of misuse of antibiotic therapies in the community. Int $J$ Antimicrob Agents 2005;26:106-13.

21 WHO. Global action plan on antimicrobial resistance. Geneva, Switzerland: World Health Organization, 2015.

22 United Nations, Department of Economic and Social Affairs, Population Division. World population prospects 2019, online edition. rev. 1, 2019.

23 UNFCCC/CCNUCC. Guidelines for sampling and surveys for CDM project activities and program of activities, Annex 5, version 2, page 18.

24 International I. Demographic and health survey interviewer's manual. MEASURE DHS basic documentation. Calverton, Maryland, U.S.A 2013.

25 Eurobarometer S. Antimicrobial resistance 2013.

26 WHO. Multi-country public awareness survey. 59. Geneva, Switzerland: World Health Organization, 2015.

27 USAID M, MACRO. Antimicrobial resistance module for populationbased surveys 2008

28 Paget J, Lescure D, Versporten A. Antimicrobial resistance and causes of non-prudent use of antibiotics in human medicine in the EU 2017.

29 Napolitano F, Izzo MT, Di Giuseppe G, et al. Public knowledge, attitudes, and experience regarding the use of antibiotics in Italy. PLoS One 2013;8:e84177.

30 Sawair FA, Baqain ZH, Abu Karaky A, Karaky AA, et al. Assessment of self-medication of antibiotics in a Jordanian population. Med Princ Pract 2009;18:21-5.

31 Shehadeh M, Suaifan G, Darwish RM, et al. Knowledge, attitudes and behavior regarding antibiotics use and misuse among adults in the community of Jordan. A pilot study. Saudi Pharm J 2012;20:125-33. 
32 Abasaeed A, Vlcek J, Abuelkhair M, et al. Self-Medication with antibiotics by the community of abu dhabi Emirate, United Arab Emirates. J Infect Dev Ctries 2009;3:491-7.

33 Al-Ramahi Rowa'. Patterns and attitudes of self-medication practices and possible role of community pharmacists in Palestine. Int J Clin Pharmacol Ther 2013;51:562-7.

34 Cheaito L, Azizi S, Saleh N, et al. Assessment of self-medication in population buying antibiotics in pharmacies: a pilot study from Beirut and its suburbs. Int J Public Health 2014;59:319-27.

35 Jassim A-M. In-Home drug storage and self-medication with antimicrobial drugs in Basrah, Iraq. Oman Med J 2010;25:79-87.

36 Widayati A, Suryawati S, de Crespigny C, et al. Self medication with antibiotics in Yogyakarta City Indonesia: a cross sectional population-based survey. BMC Res Notes 2011;4:491.

37 Mohanna M. Self-medication with Antibiotic in children in Sana'a City, Yemen. Oman Med J 2010;25:41.

38 Awadh AM, Raja AK, Mahdi Al. Assessment of knowledge, attitude and practice regarding antibiotics misuse among the public in Saudi Arabia. The Egyptian Journal of Hospital Medicine 2017;69:2405-11.
39 Moise K, Bernard JJ, Henrys JH. Evaluation of antibiotic selfmedication among outpatients of the state university hospital of Portau-Prince, Haiti: a cross-sectional study. Pan Afr Med J 2017;28:4.

40 Awad Al, Aboud EA. Knowledge, attitude and practice towards antibiotic use among the public in Kuwait. PLoS One 2015;10:e0117910.

41 Tesfaye Z. Patient knowledge and practice on antimicrobial use and resistance in Felege Hiwot Hospital, Bahir Dar, Ethiopia. Journal of Basic and Clinical Pharmacy 2017;8:S010-15.

42 Jifar ALemnesh, Ayele Y. Assessment of knowledge, attitude, and practice toward antibiotic use among harar City and its surrounding community, eastern Ethiopia. Interdiscip Perspect Infect Dis 2018;2018:1-6.

43 Vaseem A. A study on awareness and disposal practices of unused and expired medicines by consumers 2020 .

44 Michael I, Ogbonna B, Sunday N, et al. Assessment of disposal practices of expired and unused medications among community pharmacies in Anambra state Southeast Nigeria: a mixed study design. J Pharm Policy Pract 2019;12:1-10. 